\title{
LOOKING BACK AND AHEAD
}

\author{
Monty Newborn \\ Past President ICCA
}

It has been a pleasure and an honor to have served as your President for the last three years. We accomplished a number of things during that period, and I believe the coming years will be at least as exciting. In a number of years the ICCA will become the most important organisation in the world of chess!

Our successes center around the continuing overall improvement in the level of play by the programs, in the outstanding tournaments that have been held, and the improving quality of the Journal.

Our recent World Championship in Cologne was a great success. A record field of 23 programs competed for five rounds. At the end, four programs finished with four of five points and the $\$ 3000$ first prize was divided equally among them. CRAY BLITZ retained its title, and it becomes the first program ever to successfully defend its title. (They were the only champions to enter the championship as an underdog -- strange world!). This was the first tournament with prize money but not the last. The upcoming ACM North American Computer Chess Championship and ACM World Microcomputer Chess Championship in Dallas this Autumn will offer the winners a $\$ 2000$ first place prize. Prizes require a tightening of the tournament rules and an effort has been made in that direction for these ACM events. (See page 118-123 for the rules for these tournaments).

In addition to the World Championship, the 1984 and 1985 ACM North American Computer Chess Championships were succesful. HITECH, winner of the 1985 tournament, played stronger than any program to date. Its loss to CRAY BLITZ in Cologne was its first to a computer. Two World Microcomputer Championships have also been held most successfully, one in Glasgow and the most recent in Amsterdam. The quality of play of the microcomputers is increasing rapidly as is the elegance of their packaging.

Our Journal has been evolving into a world-class publication. Save your early issues; they will become collectors' items some day! I suspect that just as our organisation will become the most important in the chess world before very long, the Journal will become the most important publication. The great majority of our dues goes to support the Journal and it was neccessary for an increase, approved at our Triennial Meeting, to a $\$ 20$ US annual rate. Some efforts will also be made to reduce publishing costs which should not affect the Journal's quality. Jaap van den Herik has done an excellent job in serving as the Editor. I encourage all of you to consider the Journal as the place to publish your computer-chess material.

We voted in a new class of membership at our Triennial Meeting, that of an Institutional Member, receiving six copies for a $\$ 100$ annual fee. The first two are Intelligent Chess Software and Hegener and Glaser. This class of membership should provide increased financial stability for the Association as the commercial chess concerns become involved. It should also provide a structure around which individuals in Eastern European countries can organize their activities.

I am not planning to leave the world of computer chess. I plan to assist with the Journal and I will remain active with the ACM. Work on the Big Bird will also continue. I want to thank you all for the opportunity to have served as your Presidert. I believe the new officers will carry on and provide strong leadership for our Association over the next three years, and I wish them, David, Tony and Jonathan great success! 